\title{
SPIN-OFFS Y LA FUERZA CENTRÍFUGA DE LA UNIVERSIDAD
}

\section{SPIN-OFFS AND THE CENTRIFUGAL FORCE OF THE UNIVERSITY}

\author{
VECINO $E^{1}$
}

Aunque, durante más de una década, se ha intentado impulsar desde los distintos organismos públicos la investigación aplicada, los frutos se están empezando a ver ahora. Las convocatorias de proyectos de investigación en líneas prioritarias o aplicadas han provocado la aparición de corrientes en la investigación. Sí, la investigación también sabe de corrientes como la moda, la gastronomía o la publicidad. La investigación ha tendido hacia lo «más solicitado del momento» que ha estado asociado a «lo más financiado» del momento. Sin embargo, conseguir que una de esas corrientes se materialice en algo beneficioso para la sociedad, no es algo consustancial a todas las modas y sí es el objetivo fundamental de la ciencia. En el caso de la investigación estamos empezando a madurar lo que, durante mucho tiempo, han sido solo ideas y que se van convirtiendo en una realidad. En estos momentos podemos decir que estamos en el camino de conseguir una eficiente transmisión del conocimiento desde las universidades y centros tecnológicos a la industria. Solamente en Vizcaya, por poner un ejemplo, en el parque tecnológico de Zamudio se han instalado más de 180 empresas biotecnológicas, con una facturación que supera los 1.600 millones de euros y en cuyas instalaciones trabajan más de 6.400 personas, muchas de ellas con una alta formación. Esto ha sido posible gracias a la gran apuesta de las instituciones del País Vasco por apoyar a la iniciativa empresarial en el campo de la biotecnología.

Los objetivos prioritarios de las empresas biotecnológicas en el campo biosanitario y, por lo tanto, en la oftalmología se centran en los siguientes puntos: (1) el diseño de nuevos métodos diagnósticos, más sencillos y eficientes, capaces de detectar patologías con más precocidad y exactitud; (2) el estudio de mecanismos y vías de aplicación de los tratamientos, campos donde la tecnología farmacéutica tiene mucho que decir; y (3) los nuevos materiales y la nanotecnología aplicada a los tratamientos. Como es sabido, las grandes ideas siempre han surgido de la conjunción de diferentes puntos de vista ante un mismo problema. Así, la asociación de ingenieros, químicos, farmacéuticos, biólogos y médicos está llevando a la ciencia a un ámbito translacional.

En toda esta revolución de la ciencia y la tecnología, desarrollo e innovación, la Universidad sigue jugando una función básica. Es en la Universidad donde se forman los futuros investigadores y gestores de la ciencia aplicada $y$, a la vez, hay una exigencia escrita, pero no siempre cumplida, de que los profesores universitarios investiguen y formen a los alumnos en el pensamiento y método científicos, en las técnicas y métodos más actuales y en la práctica ejecución y correcta presentación de los resultados. Y aquí nos encontramos los profesores universitarios, en la base de lo que será el despegue económico-social de los próximos años.

Todos los que hemos pasado por la Universidad sabemos que, con honrosas excepciones, la Universidad no es el lugar ideal para dedicarse profesionalmente a la investigación, y menos si se compara con los centros específicos de investigación y tecnología que disponen de una mayor financiación, mejores infraestructuras y un modelo de gestión profesionalizado que no existe en la Universidad. Es realmente difícil que un Profesor universitario,

\footnotetext{
1 Catedrática de Biología Celular e Histología en la Universidad del País Vasco. Investigador principal del Grupo de Oftalmo-Biología Experimental y en la actualidad forma parte del Comité de Acreditación del profesorado Universitario de la ANECA en la rama de Ciencias de la Salud.

E-mail: elena.vecino@ehu.es
} 
con su equipo dedicado parcialmente a la investigación y parcialmente a la docencia, pueda competir en las mismas condiciones con un grupo profesionalizado dedicado en exclusiva a la investigación. El extremo más sangrante lo tenemos en aquellos profesores universitarios que, además de docentes, tienen una labor asistencial y a los que se les recomienda-exige una labor investigadora. Con la estructura universitaria-asistencial actual, resulta prácticamente imposible. Esto lo detectan los jóvenes investigadores, que una vez que han conseguido su base formativa e incluso el doctorado, eligen como futuro para su investigación, o bien centros de investigación tecnológica o bien empresas donde valoran su experiencia y formación.

A la Universidad, por lo tanto, le toca jugar el difícil papel de ser motor generador de conocimiento y, a la vez, lugar de frustración de científicos que ven cómo sus mejores alumnos-doctorandos deciden continuar su carrera investigadora fuera de ella. El intento de reforzar la investigación con la creación de figuras de prestigio y bien seleccionadas, como son los Contratos Ramón y Cajal, se ha convertido en un espejismo incapaz de saciar las pretensiones de los investigadores universitarios. En Finlandia se ha demostrado que la calidad de la docencia se basa fundamentalmente en el proceso de selección de los docentes, y que tras un sistema de selección estricto del profesorado, contando con las instalaciones necesarias, el prestigio social de los docentes está garantizado, así como sus frutos. En España, el intento de dignificar la figura del investigador de prestigio en la Universidad no ha cuajado. El sistema inicial de selección del personal fue serio, pero la diversidad de situaciones en cada centro receptor ha llevado a los investigadores «Cajal» a situaciones muy alejadas de lo que pretendía la iniciativa original.

En la Universidad, seguimos generando investigadores, intentando hacer ciencia competitiva, pero a expensas de tener que realizar todos y cada uno de los pasos que conlleva el proceso global de la tarea investigadora: buscar la financiación para pagar a los investigadores en formación, comprar la infraestructura, gestionar los fondos, formar al investigador y, más recientemente, contactar con empresas que puedan estar interesadas en nuestra investiga- ción. Todo esto en un entorno desfavorable en casi todos los sentidos. Hay que gestionar además el tiempo docente y el dedicado a la investigación, supeditando la elaboración de proyectos, reuniones y conferencias a los calendarios escolares. Algunas Universidades, conscientes de ello, están empezando a realizar una evaluación del profesorado en términos de eficacia investigadora, pero cambiar la mentalidad de que en la Universidad la investigación es tan prioritaria como la docencia, nos va a llevar algún tiempo, como tendrá que pasar también algún tiempo hasta que los criterios que se utilizan en la contratación del profesorado se basen en la eficacia y profesionalidad.

Es cierto que el nuevo sistema de acreditación del profesorado propone unos mínimos para llegar a ser profesor universitario, algo que no siempre se cumplía con los sistemas de oposición, pero sin duda, es necesario imponer un sistema de selección de la calidad dentro de cada Universidad, con responsabilidad. Esto quiere decir, que el seleccionador tenga que asumir la responsabilidad de la contratación y pueda llegar incluso a ser penalizado si su selección no cumple con las expectativas establecidas. Esto no es nada nuevo. En muchas Universidades americanas, donde el Departamento Universitario elige a sus futuros miembros, el comité de selección es también responsable de los frutos que dicha elección conlleva en términos de eficacia y productividad. Es decir, que lo que en otros ámbitos es bien aceptado, en la Universidad no se ha planteado aún. A ningún responsable de una clínica privada se le ocurriría contratar a un oftalmólogo que, aun teniendo una buena base teórica, no supiera utilizar la tecnología actual u operar unas cataratas. ¡La clínica perdería clientes y prestigio! Pero... ¿Dónde empieza el prestigio de una Universidad? ¿Tendremos que esperar a quedarnos sin clientes para darnos cuenta? Los finlandeses lo descubrieron hace ya muchos años y los frutos están a la vista. El secreto está en «una correcta selección de personal cualificado y profesionalizado y unas adecuadas condiciones para realizar las tareas docentes». Puesto que la Universidad es la fuente generadora de investigadores formados, germen de empresas y origen de las ideas, «demos al César lo que es del César».

No nos queda más remedio. 